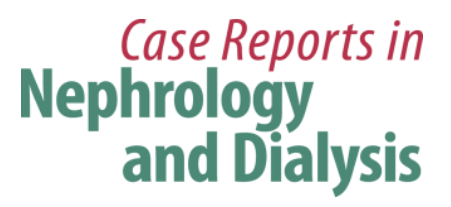

Case Rep Nephrol Dial 2017;7:91-101 DOI: $10.1159 / 000477661$

Published onlIne: June 23, 2017

(c) 2017 The Author(s)

Published by S. Karger AG, Basel

www.karger.com/cnd

This article is licensed under the Creative Commons Attribution-NonCommercial 4.0 International License (CC BY-NC) (http://www.karger.com/Services/OpenAccessLicense). Usage and distribution for commercial purposes requires written permission.

\title{
Tubuloreticular Inclusions in the Absence of Systemic Lupus Erythematosus and HIV Infection: A Report of Three Pediatric Cases
}

\author{
Ayah Elmaghrabi ${ }^{a, b} \quad$ Elizabeth Brown ${ }^{a, b} \quad$ Ei Khin $^{a, b} \quad$ Jared Hassler $^{a, b}$ \\ Allen R. Hendricks ${ }^{a}$ b \\ ${ }^{a}$ Children's Medical Center, Dallas, TX, USA; ${ }^{b}$ UT Southwestern Medical Center, \\ Dallas, TX, USA
}

\section{Keywords}

Tubuloreticular inclusions · Systemic lupus erythematosus · HIV · Cytomegalovirus

\begin{abstract}
Tubuloreticular inclusions (TRIs) are subcellular structures located within the cisternae of endoplasmic reticulum. Formation of TRIs has been linked to the exposure of excess interferon (IFN), either from endogenous or exogenous sources. In renal disease, TRIs have been most commonly associated with systemic lupus erythematosus (SLE), and human immunodeficiency virus-associated nephropathy (HIVAN). Case reports of patients with renal biopsies showing TRIs without underlying SLE or HIV are infrequent in adults, and to our knowledge none have been reported in children. We report 3 pediatric cases in which the renal biopsy showed TRIs on electron microscopy without underlying SLE or HIV infection. The first patient presented at 2 years of age with nephrotic syndrome and renal failure. His renal biopsy revealed focal segmental glomerulosclerosis and TRIs. The second patient presented at 6 months of age with infantile nephrotic syndrome, and his renal biopsy revealed membranous
\end{abstract}




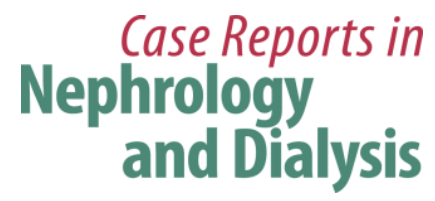

glomerulopathy and TRIs. The last patient presented at 4 years of age with acute kidney injury of unclear etiology leading to chronic kidney disease. Her biopsy revealed acute and chronic tubulointerstitial nephritis with TRIs. Despite extensive evaluation in all 3 patients, including testing for HIV infection and SLE, we could not identify an underlying etiology to explain the presence of TRIs. In conclusion, renal biopsy with TRIs in the absence of underling SLE and HIV remains obscure. We propose a possible role for excess IFN triggered by an abnormal immune response to common viral infections in the formation of TRIs and renal injury.

(C) 2017 The Author(s)

Published by S. Karger AG, Basel

\section{Introduction}

Tubuloreticular inclusions (TRIs) are 20- to 28-nm subcellular structures, made of phospholipids. They appear as anastomosing membranous tubules in the cisternae of the endoplasmic reticulum on electron microscopy (EM) [1]. They are found in endothelial and lymphoreticular cells, and other cells such as connective tissue, neural, and epithelial cells [1]. They were first described in the 1960s and had different names at different points in time [2]. TRIs have been strongly associated with systemic lupus erythematosus (SLE), human immunodeficiency virus-associated nephropathy (HIVAN), and some other viral infections [3]. Renal biopsies that show TRIs in the absence of SLE and HIV are rare and, to our knowledge, have not been reported in pediatric patients.

In this article, we report 3 pediatric patients with renal biopsy showing TRIs. Evaluation of these patients did not reveal HIV, SLE, or any other viral illness that has been reported in association with TRIs.

\section{Case Reports}

\section{Case Summary 1}

A 2-year-old Caucasian male presented with a 2-week history of fever, upper respiratory infection, and edema. He had a history of poor weight gain, and his immunizations were delayed per parent's preference. He had no family history of renal or autoimmune disease.

At presentation, he was afebrile with stable vital signs and blood pressure (BP) of 110/65 mm Hg. His weight and height were below the 5th centile for age. He had facial swelling, ascites, and significant pitting edema on his lower extremities. The remaining physical examination was unremarkable. Urinalysis (UA) revealed 4+ proteinuria with urine protein/creatinine $(\mathrm{Cr})$ ratio of 32 and no hematuria. His complete blood count (CBC) revealed anemia with hemoglobin (Hgb) of 6.4-9.9 g/dL, white blood cell count (WBC) of $6.8 \times$ $10^{3} / \mathrm{mm}^{3}$, and normal platelet count. His blood urea nitrogen (BUN) and Cr were 116 and 5.7 $\mathrm{mg} / \mathrm{dL}$, respectively. A complete metabolic panel showed hyperkalemia $(6.4 \mathrm{mg} / \mathrm{dL})$, hyperphosphatemia (9.7 mg/dL), and metabolic acidosis $(\mathrm{pH} 7.29$ and serum bicarbonate of 13 $\mathrm{mg} / \mathrm{dL})$. He also had hypermagnesemia $(3 \mathrm{mg} / \mathrm{dL})$, hypoalbuminemia $(1 \mathrm{~g} / \mathrm{dL})$, and high parathyroid hormone level of $402.7 \mathrm{pg} / \mathrm{mL}$. Complement C3 level was low at 58-65 mg/dL, and C4 was within normal limits; anti-nuclear antibody (ANA) and anti-neutrophil cyto- 


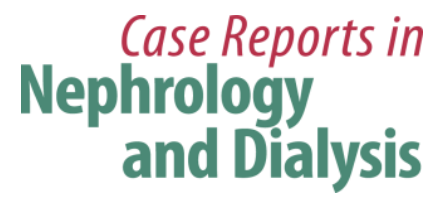

Case Rep Nephrol Dial 2017;7:91-101

(C) 2017 The Author(s). Published by S. Karger AG, Basel www.karger.com/cnd

Elmaghrabi et al.: Tubuloreticular Inclusions in the Absence of Systemic Lupus Erythematosus and HIV Infection: A Report of Three Pediatric Cases

plasmic antibodies were negative. Viral serological studies were positive only for rhinovirus/enterovirus and influenza (Table 1 ).

A kidney biopsy was performed at the time of hemodialysis catheter placement. Renal tissue was evaluated by light microscopy (LM), immunofluorescence (IF) microscopy, and EM. Extensive global glomerulosclerosis involving 33 out of 50 glomeruli was seen by LM. Fourteen glomeruli had focal segmental glomerulosclerosis (FSGS), not otherwise specified (Fig. 1a). Interstitial fibrosis and tubular atrophy was severe (approximately 70\%). Direct IF was negative for all immunoreactants including: IgG, IgA, IgM, C1q, C3, albumin, and fibrinogen. EM demonstrated extensive podocyte foot process effacement. No electron-dense deposits were identified, but TRIs were present (Fig. 1b). He was discharged to outpatient hemodialysis then transitioned to peritoneal dialysis. On subsequent visits, genetic studies showed NPHS2 mutation of unknown clinical significance. There was no sequence alteration in NPHS1, WT1, PLCE1, or LAMB2 genes.

\section{Case Summary 2}

The second case was a Hispanic male who presented at 6 months of age with nephrotic syndrome. The patient was medically complex with bilateral cataracts, hypotonia, palate deformity, developmental delay, failure to thrive with gastric tube dependency, and seizures. He had chronic respiratory failure with a history of multiple aspiration pneumonias, hypothyroidism, chronic diarrhea, and frequent urinary tract infections. His mother's antenatal screening was negative for RPR, HBV, and HIV, and she was rubella immune. There was no family history of renal or autoimmune disease. At presentation he was afebrile and BP was 92/51 mm Hg. Physical exam revealed developmental delay, hypotonia, and subtle dysmorphology which included: micrognathia, wide nasal bridge, and plagiocephaly. At the time of initial presentation, UA revealed hematuria and $3+$ proteinuria with a protein/Cr ratio of approximately 39. Urine was positive for elevated $\beta_{2}$-microglobulin. His CBC revealed anemia (Hgb 9.9-10.5 gm/dL) with normal WBC and platelets counts. BUN and Cr were normal $(5 \mathrm{mg} / \mathrm{dL}$ and $<0.1 \mathrm{mg} / \mathrm{dL}$, respectively) and he had normal electrolytes. He was hypoalbuminemic (serum albumin $1.2 \mathrm{gm} / \mathrm{dL}$ ). Viral serological studies for rhinovirus/enterovirus, coronavirus, and respiratory syncytial virus were positive. All other viral serologies were otherwise negative (Table 1). C3 and C4 were normal and ANA was negative. He had a normal karyotype without mutations in NPHS2, WT1, LAMB2, PLCE1, or NPHS1 genes. The inherited FSGS gene panel reported a likely benign variant of TRPC6. Ultrasound was initially normal, but a repeat ultrasound showed enlarged and echogenic kidneys.

A kidney biopsy was performed and evaluated by LM, IF, and EM. LM revealed mild mesangial hypercellularity and focal mild endocapillary hypercellularity. The glomerular basement membranes were diffusely thickened with spikes visible by Jones silver stain. Direct IF demonstrated diffuse, global, granular, glomerular capillary wall-positive staining by IgG (4+), IgA (3+), C1q (1+), and C3 (2+). EM showed extensive podocyte foot process effacement, numerous subepithelial electron-dense deposits (Fig. 2a), and a TRI (Fig. 2b). The combination of findings by renal biopsy was diagnostic for membranous glomerulopathy.

The patient was later diagnosed as Vici syndrome, which consists of agenesis of the corpus callosum, cataracts, oculocutaneous hypopigmentation, cardiomyopathy, and a combined immunodeficiency (molecular testing revealed biallelic mutations in the EPG5 gene). 


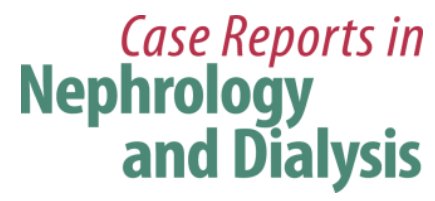

Case Rep Nephrol Dial 2017;7:91-101
\begin{tabular}{l|l}
\hline DOI: 10.1159/000477661 & $\begin{array}{l}\text { (C) } 2017 \text { The Author(s). Published by S. Karger AG, Basel } \\
\text { www.karger.com/cnd }\end{array}$
\end{tabular}

Elmaghrabi et al.: Tubuloreticular Inclusions in the Absence of Systemic Lupus

Erythematosus and HIV Infection: A Report of Three Pediatric Cases

Angiotensin converting enzyme inhibitor therapy was initiated, and his urine protein/Cr ratio decreased to 0.6 on a follow-up nephrology visit. He continued to have intermittent episodes of proteinuria and acute kidney injury during subsequent hospitalizations. The patient expired following a hospitalization for respiratory failure due to severe pneumonia, and acute respiratory distress syndrome (ARDS) which was associated with a disseminated fungal infection.

\section{Case Summary 3}

The third case was a 4-year-old female of Indian descent who presented with renal insufficiency and hyperkalemia. Two months prior to our evaluation, she had been hospitalized for acute renal failure requiring dialysis while visiting India. While in hospital she had gastroenteritis and oliguric renal failure with concern for sepsis. She required hemodialysis and plasma transfusions for worsening bilateral pneumonia and ARDS that required intubation and mechanical ventilation. Lower respiratory tract cultures grew Acinetobacter baumannii, but blood cultures remained negative. She required hemodialysis for 2 weeks after which her renal function improved and the hemodialysis catheter was removed. Upon her return to the United States, she was evaluated by her primary care physician and referred to our hospital for hyperkalemia $(6.6 \mathrm{mg} / \mathrm{dL})$. The patient's laboratory findings at that time showed elevated $\operatorname{Cr}(3.4 \mathrm{mg} / \mathrm{dL})$, hyponatremia $(113 \mathrm{mEq} / \mathrm{L})$, and increased WBC $(19.8 \times$ $10^{3} / \mathrm{mm}^{3}$ ) but no anemia or thrombocytopenia. Family history was positive for maternal Hashimoto's thyroiditis but negative for renal disease. At the time of our evaluation, the patient's only medication was pantoprazole. Physical examination at our hospital revealed an afebrile child with a BP of 114/86 mm Hg. She appeared thin and anxious but the rest of her physical exam was unremarkable. UA revealed trace leukocytes but no hematuria or proteinuria. Her CBC showed anemia (Hgb $8.9 \mathrm{~g} / \mathrm{dL}$ ), increased WBC of $12.3 \times 10^{3} / \mathrm{mm}^{3}$, normal differential count, and thrombocytosis $\left(775 \times 10^{3} / \mathrm{mm}^{3}\right)$. BUN and $\mathrm{Cr}$ were $58 \mathrm{mg} / \mathrm{dL}$ and 1.8 $\mathrm{mg} / \mathrm{dL}$, respectively. Electrolytes revealed hyperkalemia ( $6 \mathrm{mEq} / \mathrm{L})$ and hyperphosphatemia $(6.6 \mathrm{mg} / \mathrm{dL}) . \mathrm{C} 3$ and C4 were normal. ANA and anti-double-stranded DNA autoantibodies were negative. Viral serological studies were positive only for rhinovirus/enterovirus (Table 1). Renal ultrasound revealed that her right kidney had a duplicated collecting system. Renal biopsy was performed and LM showed 35 unremarkable glomeruli. Foci of mild tubulitis were seen. Interstitial fibrosis and tubular atrophy was approximately $50 \%$ with a moderate infiltrate of mononuclear leukocytes diffusely present in the interstitium (Fig. 3a). Direct IF was negative for all immunoreactants. EM showed mild podocyte foot process effacement. Definitive electron-dense deposits were not identified, but multiple TRIs were present (Fig. 3b). She was discharged home on antihypertensives (amlodipine and clonidine), erythropoietin, bicitra, and phosphate binders. Steroids were subsequently prescribed based on the biopsy diagnosis of acute and chronic tubulointerstitial nephritis. On her last follow-up, $\mathrm{Cr}$ was at $0.6 \mathrm{mg} / \mathrm{dL}$, and she had normal electrolytes.

\section{Discussion}

TRIs were originally believed to be viral particles, but were later described as discrete microstructures that directly originate from endoplasmic reticulum or as condensed materi- 


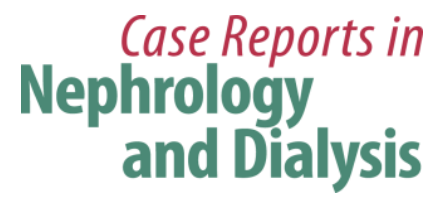

Case Rep Nephrol Dial 2017;7:91-101

(C) 2017 The Author(s). Published by S. Karger AG, Basel www.karger.com/cnd

Elmaghrabi et al: Tubuloreticular Inclusions in the Absence of Systemic Lupus Erythematosus and HIV Infection: A Report of Three Pediatric Cases

al within its cisterns $[1,2]$. They have been proposed to signify a response to cellular injury $[3,4]$. Their formation was shown to occur in response to endogenous elevation of $\alpha$ - and $\beta$ interferon and they are currently considered the footprint of interferons (IFNs) [2]. Moreover, the presence of TRIs in renal biopsies of patients with idiopathic membranous nephropathy has been shown by Yang et al to indicate the existence of underlying autoimmune or viral etiology [5]. TRIs have been historically associated with SLE and HIV infection since the late 20 th century.

In the early 1980s, Rich et al. [6] demonstrated the association between secretion of IFN and the formation of TRIs, which were named "lupus inclusions" at the time. Subsequently, Kim et al. [7], in the late 1980s, reported increased levels of IFN- $\alpha$ in patients with SLE. Furthermore, IFN- $\alpha$ has been shown to induce SLE through the activation of antigen-presenting cells and autoimmunity [8]. Moreover Nakahara et al. [9] described TRIs as an earlier sign of SLE that can even precede glomerulonephritis with "full-house" IF staining. None of our 3 cases had positive serology for lupus, nor did they show clinical signs and or symptoms of SLE during the follow-up period.

TRIs have been also associated with HIV infection since the late 1980s. Strauss et al. [10] reported the presence of TRIs in 10 out 10 patients with HIVAN, and Cohen et al. [11] considered the combination of renal lesions including FSGS and TRI specific for HIVAN diagnosis. Later, the presence of TRIs and the collapsing variant of FSGS was linked to HIV infection [12].

Although the pathogenesis of HIVAN remains unclear, there is recent evidence for direct infection of the renal epithelial cells as the underlying etiology [13]. Our 3 patients were investigated for HIV infection and found to be negative.

Bromfield et al. [14] reported a case of FSGS and TRIs in a renal biopsy from a patient with cytomegalovirus (CMV) infection. They concluded that CMV might have triggered an exaggerated T-cell response that led to the development of podocyte injury as well as the TRIs. All of our cases were tested for CMV and found to be negative.

INFs $\alpha$ and $\beta$ have been shown to induce podocyte loss, proteinuria, and glomerular sclerosis [15]. Wallbach et al. [16] described the ability of INF to either suppress or augment immune response, and in their case report of a multiple sclerosis patient treated with INF, they concluded that proteinuria, nephrotic syndrome, and lupus nephritis should be regarded as uncommon adverse effects of INF- $\beta$ therapy. Similarly, Markowitz et al. [17] reported 11 cases of collapsing FSGS after treatment with IFNs. Ten out of 11 had endothelial TRIs. The authors emphasized the importance of considering collapsing FSGS with TRIs as a wellrecognized consequence of INF therapy.

The underlying etiology for the formation of TRIs in our patients remains unclear. Although all 3 of our patients were negative for HIV and CMV, they did test positive for other common viruses (Table 1). Viral infections induce IFN production triggering signaling systems linked to toll-like receptors (TLRs) $[18,19]$. Our 3 patients may have had elevated endogenous IFN triggered by an exaggerated immune response to common viral infections. Serological studies to determine IFN levels and immunohistochemical (IHC) staining to detect enhanced TLR expression in our patients may have been very informative. A finding of elevated IFN and positive TLR tissue staining would have added valuable evidence in support of our hypothesis that common viral infections as found in our patients can result in 
formation of TRIs. Unfortunately, by the time these cases were examined for publication, it was too late to perform serological studies and TLR staining was not available to us.

In conclusion, the presence of TRIs in renal biopsies of children without underlying autoimmune or viral etiologies remains obscure. We propose a possible role for excess IFN triggered by an abnormal immune response to common viral infections in the formation of TRIs and the renal injury. Performing serological testing for IFN levels and TLR IHC stains in patients similar to the ones we have described may be useful in future studies if performed immediately after discovery of TRIs within the renal biopsy.

\section{Statement of Ethics}

The authors have no ethical conflicts to declare.

\section{Disclosure Statement}

The authors declare no conflict of interest.

\section{References}

1 Grimley PM, Schaff Z: Significance of tubuloreticular inclusions in the pathobiology of human diseases. Pathobiol Annu 1976;6:221-257.

-2 Luu JY, Bockus D, Remington F, Bean MA, Hammar SP: Tubuloreticular structures and cylindrical confronting cisternae: a review. Hum Pathol 1989;20:617-627.

- 3 Lee CJ, Suh KS, Kim KH, Chang YK, Na KR, Lee KW: The clinicopathologic significance of endothelial tubuloreticular inclusions in glomerular diseases. Ultrastruct Pathol 2013;37:386-394.

4 Schaff Z, Heine U, Dalton AJ: Ultramorphological and ultracytochemical studies on tubuloreticular structures in lymphoid cells. Cancer Res 1972;32:2696-2706.

5 Yang AH, Lin BS, Kuo KL, Chang CC, Ng YY, Yang WC: The clinicopathological implications of endothelial tubuloreticular inclusions found in glomeruli having histopathology of idiopathic membranous nephropathy. Nephol Dial Transplant 2009;24:3419-3425.

6 Rich SA: Human lupus inclusions and interferon. Science 1981;213:772-775.

7 Kim T, Kanayama Y, Negoro N, Okamura M, Takeda T, Inoue T: Serum levels of interferons in patients with systemic lupus erythematosus. Clin Exp Immunol 1987;70:562-569.

-8 Niewold TB, Swedler WI: Systemic lupus erythematosus arising during interferon-alpha therapy for cryoglobulinemic vasculitis associated with hepatitis C. Clin Rheumatol 2005;24:178-181.

-9 Nakahara C, Hayashi D, Kinugasa H, Horigome H, Matsui A, Takagi A, et al: Delayed onset of systemic lupus erythematosus in a child with endothelial tubuloreticular inclusion. Clin Nephrol 2001;56:332335.

10 Strauss J, Abitbol C, Zilleruelo G, Scott G, Paredes A, Malaga S, et al: Renal disease in children with the acquired immunodeficiency syndrome. N Engl J Med 1989;321:625-630.

-11 Cohen AH, Nast CC: HIV-associated nephropathy. A unique combined glomerular, tubular, and interstitial lesion. Mod Pathol 1988;1:87-89.

12 Madiwale C, Venkataseshan VS: Renal lesions in AIDS: a biopsy and autopsy study. Indian J Pathol Microbiol 1999;42:45-54.

13 Medapalli RK, He JC, Klotman PE: HIV-associated nephropathy: pathogenesis. Curr Opin Nephrol Hypertens 2011;20:306-311.

14 Bromfield M, McQuillan R, John R, Avila-Casado C: The significance of tubuloreticular inclusions as a marker of systemic stimulation by interferons in a case of focal and segmental glomerulosclerosis associated with cytomegalovirus (CMV) infection. Clin Kidney J 2014;7:174-178. 
Elmaghrabi et al.: Tubuloreticular Inclusions in the Absence of Systemic Lupus

Erythematosus and HIV Infection: A Report of Three Pediatric Cases

15 Migliorini A, Angelotti ML, Mulay SR, Kulkarni 00, Demleitner J, Dietrich A, et al: The antiviral cytokines IFN-alpha and IFN-beta modulate parietal epithelial cells and promote podocyte loss: implications for IFN toxicity, viral glomerulonephritis, and glomerular regeneration. Am J Pathol 2013;183:431-440. Wallbach M, Grone HJ, Kitze B, Muller GA, Koziolek MJ: Nephrotic syndrome in a multiple sclerosis patient receiving long-term interferon beta therapy. Am J Kidney Dis 2013;61:786-789.

17 Markowitz GS, Nasr SH, Stokes MB, D'Agati VD: Treatment with INF- $\alpha,-\beta$, or $-\gamma$ is associated with collapsing focal segmental glomerulosclerosis. Clin J Am Soc Nephrol 2010;5:607-615.

-18 Malmgaard L: Induction and regulation of IFNs during viral infections. J Interferon Cytokine Res 2004;24:439-454.

19 Borden EC, Sen GC, Uze G, et al: Interferons at age 50: past, current and future impact on biomedicine. Nat Rev Drug Discov 2007;6:975-990. 


\section{Case Reports in Nephrology and Dialysis}

Case Rep Nephrol Dial 2017;7:91-101

(C) 2017 The Author(s). Published by S. Karger AG, Basel DOI: $10.1159 / 000477661$ www.karger.com/cnd

Elmaghrabi et al: Tubuloreticular Inclusions in the Absence of Systemic Lupus Erythematosus and HIV Infection: A Report of Three Pediatric Cases

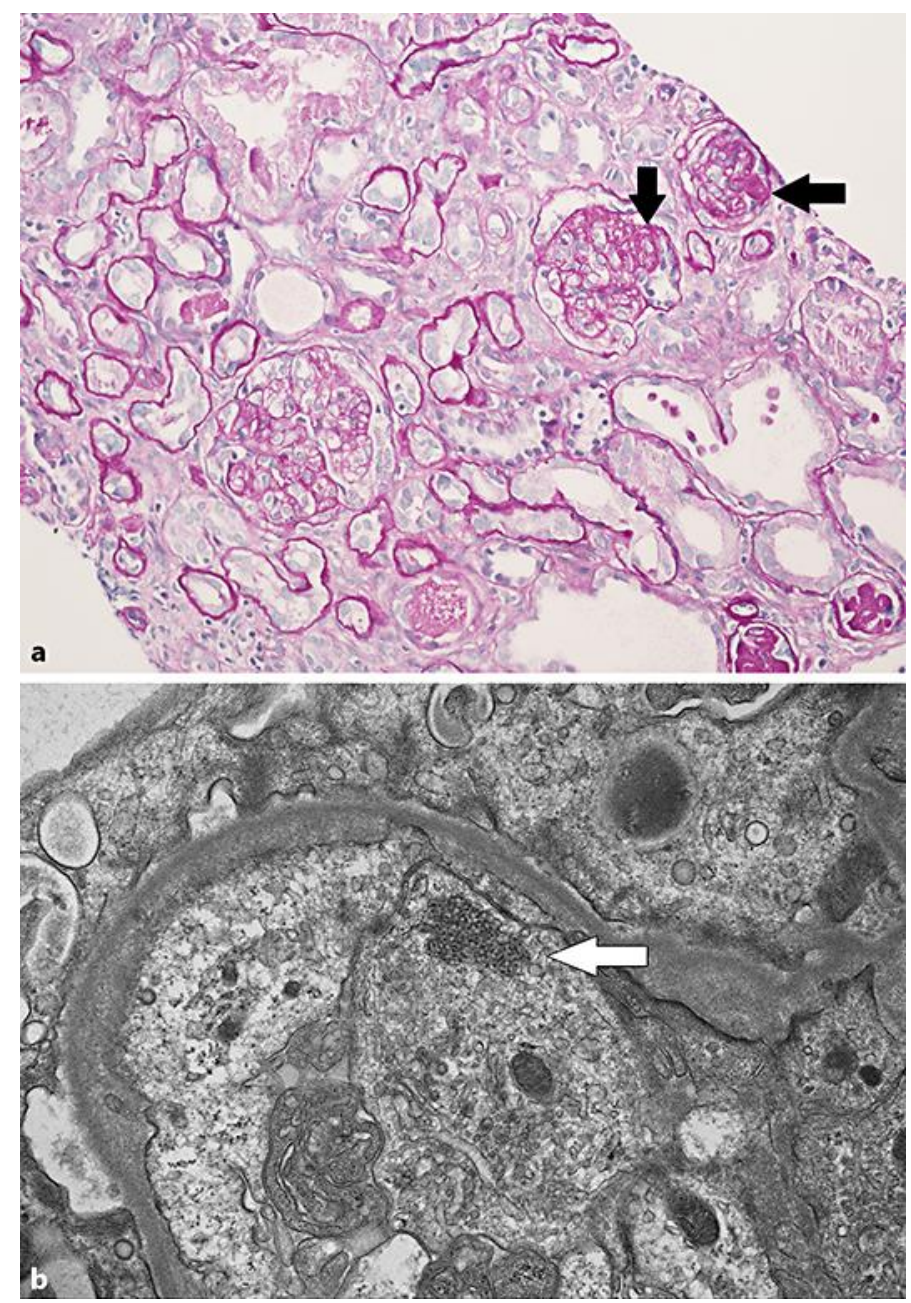

Fig. 1. Renal biopsy findings for case 1. a Three glomeruli with focal and segmental sclerosis (arrows), not otherwise specified (periodic acid-Schiff; original magnification $\times 20$ ). b Electron microscopy shows tubuloreticular inclusions (arrow) within glomerular endothelial cell cytoplasm (original magnification $\times 8,000)$. 


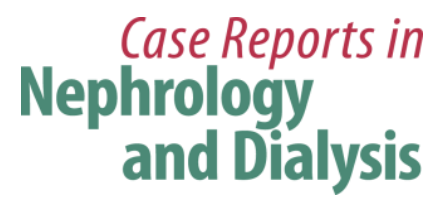

(C) 2017 The Author(s). Published by S. Karger AG, Basel www.karger.com/cnd

Elmaghrabi et al: Tubuloreticular Inclusions in the Absence of Systemic Lupus

Erythematosus and HIV Infection: A Report of Three Pediatric Cases

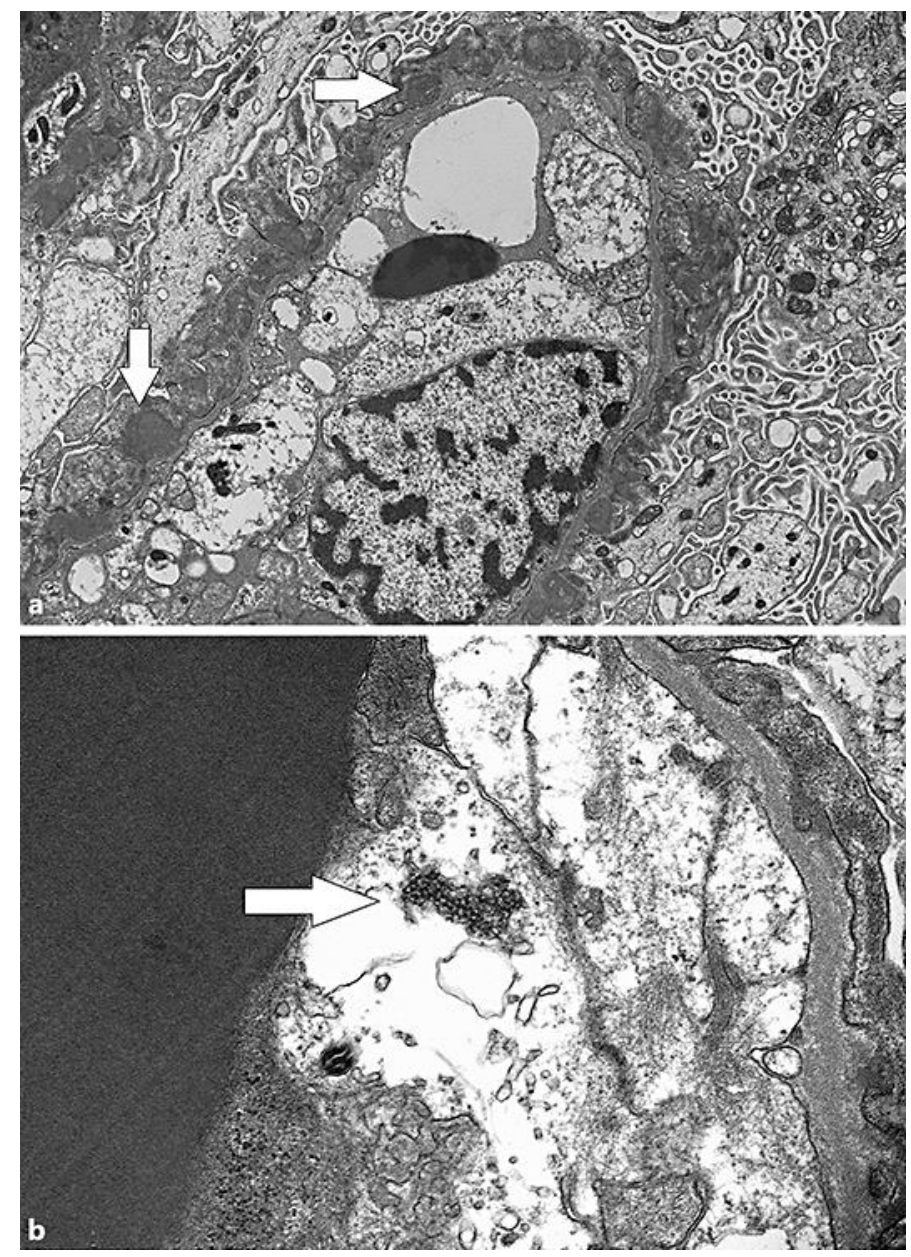

Fig. 2. Renal biopsy findings for case 2. Electron microscopy shows subepithelial electron-dense deposits (arrows; original magnification $\times 3,000$ ) (a) and a tubuloreticular inclusion (arrow) within cytoplasm of an endothelial cell (original magnification $\times 12,000)($ b). 


\section{Case Reports in Nephrology and Dialysis}

Case Rep Nephrol Dial 2017:7:91-101

(C) 2017 The Author(s). Published by S. Karger AG, Basel DOI: $10.1159 / 000477661$ www.karger.com/cnd

Elmaghrabi et al.: Tubuloreticular Inclusions in the Absence of Systemic Lupus Erythematosus and HIV Infection: A Report of Three Pediatric Cases

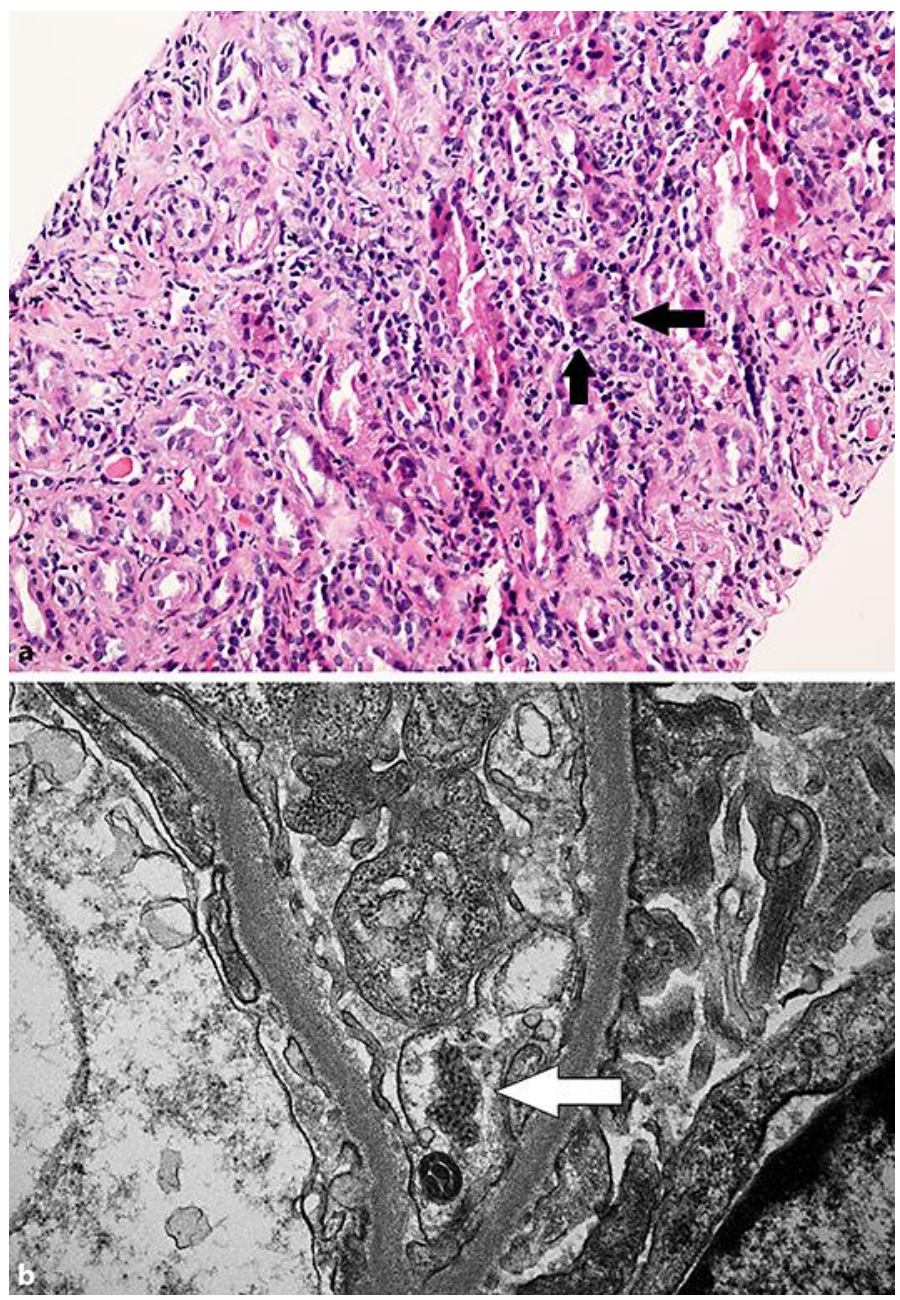

Fig. 3. Renal biopsy findings for case 3. a Mononuclear leukocytes infiltrate tubules (arrows) along with intact and fibrotic interstitium (hematoxylin and eosin; original magnification, $\times 20$ ). $\mathbf{b}$ Electron microscopy of glomeruli shows a tubuloreticular inclusion (arrow) within cytoplasm of an endothelial cell (original magnification $\times 12,000$ ). 
Elmaghrabi et al.: Tubuloreticular Inclusions in the Absence of Systemic Lupus

Erythematosus and HIV Infection: A Report of Three Pediatric Cases

Table 1. Summary of serologic tests

\begin{tabular}{llll}
\hline Test & Case 1 (FSGS) & $\begin{array}{l}\text { Case 2 (membranous } \\
\text { glomerulopathy) }\end{array}$ & $\begin{array}{l}\text { Case 3 (acute and } \\
\text { chronic TIN) }\end{array}$ \\
\hline HIV & Negative & Negative & Negative \\
Hepatitis B & Negative & Negative & Negative \\
Hepatitis C & Negative & Negative & Negative \\
CMV & Negative & Negative & Negative \\
Parvovirus B19 & Negative & Negative & Not available \\
EBV & Negative & Negative & Negative \\
Rhinovirus/enterovirus & Positive & Positive (after biopsy) & Positive (after biopsy) \\
Coronavirus & Negative & Positive & Negative (after biopsy) \\
RSV & Negative & Positive & Negative (after biopsy) \\
Influenza & Positive & Negative & Negative (after biopsy) \\
ANA & Negative & Negative & Negative \\
C3 and C4 & Low C3, normal C4 & Normal C3 \& C4 & Normal C3 \& C4 \\
\hline
\end{tabular}

TIN, tubulointerstitial nephritis; EBV, Epstein-bar virus; CMV, cytomegalovirus; RSV, respiratory syncytial virus; ANA, antinuclear antibodies; C3, complement 3; C4, complement 4. 